\section{The use of an endo- tracheal ventilation catheter for jet ventilation during a difficult intubation}

Richard M. Cooper BSc MSc MD FRCPC, David R. Cohen BSc MD FRCPC
This case report describes the use of an endotracheal ventilation catheter (ETVC) to provide prolonged intraoperative jet ventilation, reintubation and the maintenance of tracheal access following extubation. It emphasizes that excellent oxygenation and ventilation can be achieved but such management can be complicated by a pneumothorax even when the risks are minimized. A 43-yr-old man presented for possible pulmonary sleeve resection. Placement of a double lumen endotracheal tube (DLT) by direct laryngoscopy was unsuccessful due to the inability to visualize the glottis. $A 7.5 \mathrm{~mm}$ endotracheal tube (ETT) was successfully introduced over a fibreoptic bronchoscope (FOB). An ETVC was passed, permitting manually cycled jet ventilation while general intravenous anaesthesia and muscle relaxation were maintained. The ETT was then withdrawn over the ETVC and jet ventilation continued for approximately 90 min, while attempts at placing a DLT over a now malfunctioning FOB continued. These attempts were eventually abandoned and the patient was returned to the post-anaesthesia care unit (PACU) haemodynamically stable. The trachea was extubated over the ETVC, which remained in situ. A pneumothorax was noted on the postoperative chest $x$-ray. This case illustrates prolonged intraoperative jet injection via a "jet stylet" with satisfactory ventilation and oxygenation but complicated by a pneumothorax. Also it illustrates a strategy for the management of a "difficult extubation."

\section{Key words}

COMPLICATIONS: pneumothorax;

EQUIPMENT: tubes: endotracheal, double-lumen, endotracheal ventilation catheter; INTUBATION: complications, difficult; VENTILATION: jet.

From the Department of Anaesthesia, The Toronto Hospital, 200 Elizabeth St., Toronto, Ontario, M5G 2 C4. Address correspondence to: Dr. R.M. Cooper. Accepted for publication 5th August, 1994.
Cette observation décrit l'utilisation d'un cathéter de ventilation endotrachéale (CEVT) pour réaliser la ventilation peropératoire prolongée, la réintubation et le maintien d'un abord trachéal après l'extubation. Elle met l'accent sur l'excellence de l'oxygénation et de la ventilation obtenue avec cette technique mais rappelle qu'elle peut être compliquée d'un pneumothorax malgré toutes les précautions habituelles. Un homme de 43 ans se présente pour une résection pulmonaire partielle. La mise en place d'un tube endotrachéal à deux lumières (TDL) avorte parce quil s'avère impassible de visualiser la glotte. Un tube endotrachéal (TET) de $7,5 \mathrm{~mm}$ est introduit avec succès sur un fibroscope (FOB). Un CEVT est introduit et permet le maintien d'une ventilation à jet manuellement contrôlée pendant une anesthésie générale intraveineuse avec relaxation musculaire. Le TET est ensuite retiré par-dessus le CEVT et la ventilation par jet est prolongée pendant environ 90 min alors que sont effectués des essais de mise en place d'un TDL sur un FOB qui s'est mis à mal fonctionner. Ces tentatives sont éventuellement abandonnées et le malade hémodynamiquement stable est ramené en salle de réveil. La trachée est extubée sur le CEVT qui reste en place. On décèle un pneumothorax sur la radiographie postopératoire. Cette observation illustre un cas de ventilation par jet injection par un stylet avec une ventilation et une oxygénation satisfaisantes mais qui se complique d'un pneumothorax. Elle illustre aussi une stratégie applicable à la gestion de l'extubation difficile.

Transtracheal jet ventilation has been advocated in the management of the "can't intubate, can't ventilate" patient. ${ }^{1}$ Also, jet ventilation via a "jet stylet $^{\text {"2 }}$ has been proposed as a means of maintaining gas exchange following extubation or during reintubation of a difficult airway. While such a strategy may be life-saving, the potential complications need to be identified and considered. The few cases described in the literature generally involve brief jet ventilation. The following case involved complete ventilatory support for $90 \mathrm{~min}$ with excellent gas exchange but was complicated by a pneumothorax. 


\section{Case report}

A 43-yr-old oriental man presented with paroxysmal coughing and scant haemoptysis. Outpatient evaluation including a chest $x$-ray, CT chest, and awake fibreoptic bronchoscopy, revealed an obstructing polypoid lesion in a proximal right upper lobe bronchus. Biopsies were consistent with a neuroendocrine tumour.

Preoperative evaluation revealed a fit patient with a long neck, a protruding thyroid cartilage and a small mandible (Mallampati class I). He was premedicated with glycopyrrolate and taken to the operating room where, following preoxygenation, and with a fibreoptic bronchoscope (FOB) on standby, general anaesthesia and muscle relaxation were induced with thiopentone and succinylcholine. Bag and mask ventilation was easily achieved, but laryngoscopy with Macintosh (\#3 and \#4) and Miller (\#3) blades was unsuccessful. Tracheal intubation was easily achieved by passing a $7.5 \mathrm{~mm}$ ETT over a FOB.

Surgical considerations necessitated a double lumen endotracheal tube (DLT). An endotracheal ventilation catheter (ETVC) (CardioMed Supplies Inc., Gormley, Ontario) was introduced through the ETT. Its distance markings coincided with those of the ETT ensuring proper depth of insertion. The ETVC was inserted to maintain continuous airway access and to serve as a delivery system for jet ventilation. The ETT was opened to atmosphere, its cuff deflated and the ETVC was connected to a hand-held Sanders jet injector with a pressure regulator (Jet Ventilator, CardioMed Supplies, Figure 1). The jet injector was adjusted to the lowest level required to achieve adequate chest expansion (20 pounds per square inch) and the ETT was withdrawn from the trachea. General anaesthesia was achieved with midazolam, propofol and fentanyl. Muscle relaxation was provided by succinylcholine. Manually cycled jet ventilation continued at approximately ten breaths per minute with an I:E ratio of about 1:5. The ETVC was of insufficient length to serve as a tube exchanger for the DLT and attempts at fibreoptic placement of the DLT alongside the ETVC were frustrated by a now completely broken angulation control wire on the bronchoscope. No other FOB was available. Jet ventilation continued in this manner for $90 \mathrm{~min}$ with haemodynamic stability, good arterial saturation and chest expansion. Arterial blood gases taken at 90 minutes showed a pH 7.47, $\mathrm{PaCO}_{2}$ $34 \mathrm{mmHg}$ and $\mathrm{PaO}_{2} 470 \mathrm{mmHg}$. Due to the inabiliy to place the DLT with the available equipment, the procedure was aborted. Reintubation with a single lumen ETT was easily achieved over the ETVC and the patient was taken to the PACU. Spontaneous ventilation was quickly established and the trachea was extubated over the ETVC. A routine chest $x$-ray revealed an $80 \%$ right pneu-

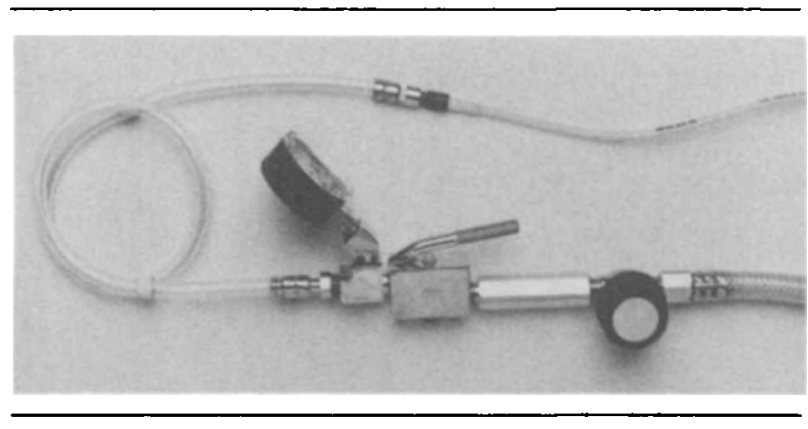

FIGURE 1 An ETVC (CardioMed Supplies) connected to a handheld, adjustable jet injector (Jet Ventilator, CandioMed Supplies).

mothorax requiring placement of a chest tube. The ETVC, which was well tolerated, was removed several hours later when the patient was fit to be discharged from the PACU.

Two weeks later he returned to the operating room for definitive surgery. With a functioning paediatric bronchoscope, topical oral anaesthesia, superior laryngeal and glossopharyngeal nerve blocks, awake fibreoptic placement of a 37 French Ruisch DLT into the left main bronchus was achieved with little difficulty and resection of an endocrinologically silent carcinoid tumour of the right upper lobe was performed. The trachea was extubated over the ETVC and the patient made an uneventful recovery.

\section{Discussion}

The ETVC was developed as a modification of Bedger's "jet stylet." It is a semi-rigid plastic catheter, $65 \mathrm{~cm}$ long, with outer and inner diameters of approximately 4 and $3 \mathrm{~mm}$ respectively. It has a distal end hole and multiple distal side-holes (Figure 2). At its proximal end, there is a removable Luer lock fitting to provide a secure attachment to a source of high pressure oxygen (Figure 1). it was designed primarily as a means of maintaining airway access, following extubation. Once in place, it may be used to provide supplemental oxygen by insufflation or jet ventilation, while serving as an introducer over which an endotracheal tube may be passed.

The use of a "jet stylet" for jet ventilation has been previously described. ${ }^{2-4,6,7}$ Bedger and Chang ${ }^{3}$ introduced their jet stylet through a rigid bronchoscope in one patient, and a damaged ETT in another, providing "brief" ventilation. They also mentioned that they had used the catheter for jet ventilation in six patients without complication, but their paper provided no details concerning the indications or a description of the technique employed. Egol described barotrauma in three ICU patients using various "stylets" (tracheal suction catheter, gastric sump 


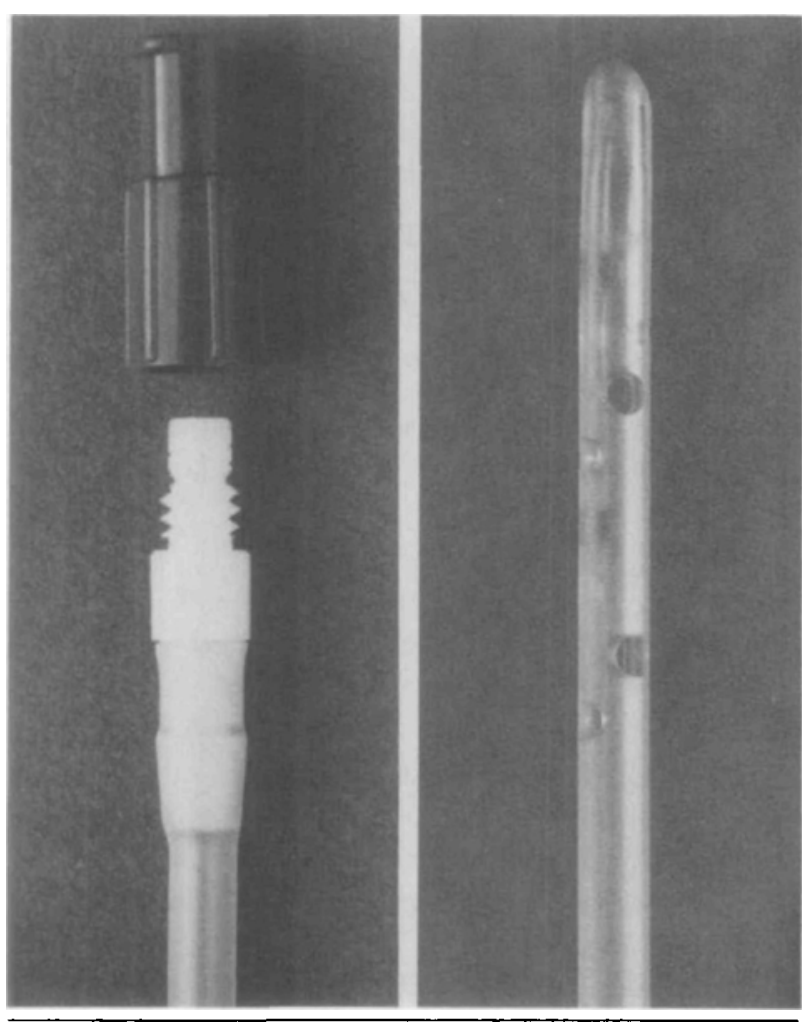

FIGURE 2 The left hand panel shows the removable Luer lock connector at the proximal end of the ETVC. The right hand panel shows the distal end of the ETVC with an end hole and helically arranged side holes.

tube and a fibreoptic laryngoscope) at driving pressures of $20-50 \mathrm{psi}^{8}{ }^{8}$ These were felt to result from incorrect catheter placement, jet ventilation in a phonating patient with resultant glottic closure and possibly direct tissue injury from jet injection. Chang et al. ${ }^{6}$ described one case of abdominal distention and three cases of pneumothoraces resulting from jet ventilation through a $3.5 \mathrm{~mm}$ paediatric chest tube. Cooper ${ }^{7}$ described the use of the ETVC for the intraoperative ventilation of 15 patients during percutaneous dilatational tracheostomies.

Egol $^{8}$ compared a variety of delivery devices and demonstrated that the pressure at the distal end was inversely related to the number of side holes. In this respect, the ETVC, with one end hole and eight side holes is well suited for jet ventilation. The side holes reduce distal pressure, minimize catheter whip, centering the catheter within the trachea, reducing the likelihood of direct injection injury. Despite this, the present report describes a patient whose lungs were well ventilated and oxygenated for $90 \mathrm{~min}$, with no haemodynamic compromise but who developed a clinically inapparent pneumothorax.

Apart from the neuroendocrine tumour, this patient had normal lungs. Muscle relaxation and normal lung compliance permitted satisfactory ventilation at a relatively low inflation pressure. Using a manually cycled interrupter, an effort was made to restrict inspiratory and maximize expiratory time, judged clinically by chest expansion and recoil. While arterial blood gases taken after $90 \mathrm{~min}$ of jet ventilation revealed excellent oxygenation and ventilation, the patient developed a pneumothorax. This could also have resulted from (i) gas penetrating directly through tissue planes, ${ }^{8}$ (ii) tracheal instrumentation, ${ }^{9,10}$ although no injury could be identified in the proximal airways and no resistance to insertion was encountered, (iii) the polypoid lesion may have served as a ball-valve, permitting entry of gas under positive pressure, but restricting its egress, or (iv) malplacement of the catheter into the right bronchus resulting in overdistention or excessive alveolar pressure.

The mechanism of ventilation during jet injection may depend upon the specific method of application. Gaughan et al. ${ }^{11}$ evaluated three sizes of Sheridan Tracheal Tube Exchangers, an injector at $50 \mathrm{psi}$, using a pneumotachograph and a mechanical lung with variable compliance. The upper airway was simulated by a $14-\mathrm{cm}$ segment of 22-mm-ID, corrugated plastic tube, opened to atmosphere and connected to a pneumotachograph to measure entrained air. They found that entrainment varied from $0-31 \%$. The greatest degree of entrainment occurred with the largest lung compliance and the largest diameter exchange catheter. In this case, we made no direct measurement air entrainment; however, the arterial $\mathrm{PaO}_{2}$ of $470 \mathrm{mmHg}$, particularly if the pneumothorax already existed, makes considerable entrainment unlikely.

One of the authors (RMC) has used the ETVC as a means of providing jet ventilation in 44 patients. Many of these were ICU patients who were ventilatordependent, with abnormal pulmonary compliance and resistance. All but one were anaesthetized and paralyzed. Until recently, ventilation was always provided at $50 \mathrm{psi}$. Barotrauma has complicated five of these procedures. Most of these were believed to be due to catheter migration, distally into a bronchus or proximally into the oropharynx. Despite the high ventilation pressures, low pulmonary compliance may have provided some protection against lung over-inflation or "volotrauma."12

In the case described, having secured the airway by intubation over a FOB, the ETVC ideally would have served as a stylet over which the DLT could have been passed. Unfortunately, the ETVC has too large an outer diameter and like the Sheridan tracheal tube exchanger (Sheridan Catheter Corp. Argyle, NY) is too short ${ }^{13}$ to serve this purpose. A modified ETVC for the DLT is currently being developed by the manufacturer (personal communication) and has recently become available from 
Sheridan Catheter Corporation (E.T.X.(1), personal communication). However, the catheter was used to reintubate the trachea successfully with a single lumen ETT and to maintain access to the trachea following extubation.

Clinical use of a "jet stylet" has been advocated for the extubation and/or reintubation of the difficult airway. ${ }^{1,3-5}$ It allows continuous airway access and can be used for oxygen insufflation, jet ventilation or capnography during or after extubation or reintubation. Such a device has been incorporated into the American Society of Anesthesiologists' airway algorithm, ${ }^{5}$ although clinical studies have been limited to case reports and in vitro descriptions of gas flow."

The importance of this case is that it demonstrates that jet ventilation, via a tracheal catheter, can provide excellent oxygenation and ventilation for a considerable period of time. However, even with low driving pressures, apparently correct catheter placement and no evidence of upper airway obstruction, the risk of barotrauma exists. We recommend that when using devices such as the ETVC, consideration be given to the need for jet ventilation. If jet ventilation is deemed essential to the maintenance of acceptable gas exchange, extreme care should be taken to use low driving pressures while minimizing airway resistance, minimizing inspiratory and maximizing expiratory times.

\section{References}

1 Benumof JL. Management of the difficult adult airway. With special emphasis on awake tracheal intubation. Anesthesiology 1991; 75: 1087-110.

2 Benumof JL, Gaughan SD, Ozaki GT, Rusk R. Connecting a jet stylet to a jet injector (Letter). Anesthesiology 1991; 74: 963-4.

3 Bedger RC Jr, Chang J-L. A jet-stylet endotracheal catheter for difficult airway management. Anesthesiology 1987; 66: 221-3.

4 Cooper RM. Use of an endotracheal ventilation catheter for difficult extubations. Anesthesiology 1992; 77: A107.

5 Caplan RA, Benumof JL, Berry FA, et al. Practice guidelines for management of the difficult airway, a report by the American Society of Anesthesiologists Task Force on Management of the Difficult Airway. Anesthesiology 1993; 78: $597-602$.

6 Chang J-L, Bleyaert A, Bedger RC. Unilateral pneumothorax following jet ventilation during general anesthesia. Anesthesiology 1980; 53: 244-6.

7 Cooper RM, Irish JC, Brown DH. A new technique for percutaneous dilatational tracheostomies using an endotracheal ventilation catheter. Can J Anaesth 1993; 40: A71.

8 Egol A, Culpepper JA, Snyder JV. Barotrauma and hypotension resulting from jet ventilation in critically ill patients. Chest 1985; 88: 98-102.
9 deLima $L$, Bishop $M$. Lung laceration after tracheal extubation over a plastic tube changer. Anesth Analg 1991; 73: 350-1.

10 Seitz $P A$, Gravenstein $N$. Endobronchial rupture from endotracheal reintubation with an endotracheal tube guide. J Clin Anesth 1989; 1: 214-7.

11 Gaughan SD, Benumof JL, Ozaki GT. Quantification of the jet function of a jet stylet. Anesth Analg 1992; 74: 580-5.

12 Zapol WM. Volotrauma and the intravenous oxygenator in patients with adult respiratory distress syndrome (Editorial). Anesthesiology 1992; 77: 847-9.

13 Hannallah M. Evaluation of Tracheal Tube Exchangers ${ }^{\circledR}$ for replacement of double-lumen endotracheal tubes (Letter). Anesthesiology 1992; 77: 609-10. 